\title{
Invasive Group B Streptococcus Infections in Adults, England, 2015-2016
}

\author{
Simon M. Collin, Nandini Shetty, Theresa Lamagni
}

During 2015-2016, a total of 3,156 episodes of invasive group B Streptococcus (iGBS) infection in adults $(\geq 15$ years of age) were recorded in England, corresponding to an annual incidence of $4.09 / 100,000$ population. iGBS incidence was highest in older patients and women of childbearing age. The 493 pregnancy-related iGBS episodes correspond to a rate of $1.34 / 10,000$ live births. In adults up to 60-69 years of age and in pregnant women, iGBS incidence increased with higher levels of socioeconomic deprivation. Hospital admissions associated with iGBS were predominantly emergency admissions $(73 \%$ $[2,260 / 3,099]) ;$ only $7 \%$ of nonpregnancy iGBS diagnoses were made $\geq 48$ hours after admission. Underlying conditions were highly prevalent in nonpregnant adult casepatients, including cardiovascular $(57 \%)$, lung (43\%), and kidney $(45 \%)$ disease and diabetes (40\%). Post-iGBS episode 30-day and 12-month all-cause mortality rates in nonpregnant adults were $12 \%$ and $24 \%$, respectively. No pregnancy-related iGBS deaths were identified.

Streptococcus agalactiae (group B Streptococcus; GBS) $\mathcal{S}$ is implicated in a range of clinical manifestations in adults, including surgical site, skin and soft tissue, and urinary tract infections (1-3). Invasive GBS (iGBS) disease in adults is of growing clinical and public health concern (4-6), with incidence in England and Wales during 1996-2010 increasing almost 3-fold (7). The increasing prevalence of known risk factors for iGBS disease, including old age and underlying conditions such as diabetes (8-11), means that considerable healthcare, economic, and social costs will be associated with iGBS disease in adults. The advent of vaccines to prevent neonatal GBS disease raises the possibility of preventing iGBS disease in other patient groups (12). However, although neonatal iGBS has been the subject of epidemiologic research for several decades (13), adult iGBS disease is less well characterized.

Author affiliation: National Infection Service, Public Health England, London, UK

DOI: https://doi.org/10.3201/eid2606.191141
The aim of this study was to characterize iGBS disease in adults by creating a national retrospective cohort of cases in England identified through laboratory surveillance linked to hospital admissions data. Our objectives were to describe characteristics of adults who received diagnoses of iGBS; time to infection, medical specialty, and healthcare resource use in patients admitted to a hospital within 7 days of diagnosis; concurrent conditions and surgery in current and prior admissions up to 1 year before diagnosis; and all-cause mortality within 30 days and within 1 year of an iGBS episode.

\section{Methods}

\section{Case Definition}

We defined iGBS infection through the isolation of $S$. agalactiae recorded in specimens from a normally sterile site, such as blood, cerebrospinal fluid, joint fluid, bone, pleural fluid, bronchoalveolar lavage, ascitic fluid, lymph node biopsy/aspirate, pericardial fluid, heart valve, brain abscess, or other organs. We considered laboratory test result records within 14 days to be part of the same episode and merged them accordingly.

\section{PHE Second Generation Surveillance System}

We extracted laboratory-confirmed cases of iGBS infection diagnosed from specimens taken during January 1, 2015-December 31, 2016 from the Public Health England (PHE) Second Generation Surveillance System (SGSS), the national communicable disease surveillance database, for analysis. SGSS collates microbiological diagnoses from laboratories across England (including all National Health Service [NHS] laboratories), primarily through automated upload (14-16). In addition to information about the laboratory, specimen, test method, and type of infection, SGSS records include patient identifiers and demographic data (name, sex, date of birth, and the patient's NHS number). 


\section{Hospital Episode Statistics}

We identified corresponding hospital admissions for episodes of iGBS infection through record linkage to Hospital Episode Statistics (HES; https:/ / digital.nhs. uk). HES includes all NHS secondary care activity (98\% of all hospital activity in the country [17]) that requires a hospital bed, including emergency and planned (elective) admissions, day cases, and births. HES admitted patient care data are collated by NHS Digital to reimburse NHS hospitals for the costs of care (using Healthcare Resource Group codes to group diagnoses and interventions). These data provide clinical, demographic and organizational information, including data on diagnoses and procedures, concurrent conditions (by code from the International Classification of Diseases, 10th Revision [ICD-10]), dates of admission, admission method (emergency or elective), care provider, and geographic variables mapped from a patient's postcode.

\section{Data Linkage and Statistical Analysis}

Our analysis of hospital admissions associated with iGBS episodes used a dataset created by linking SGSS laboratory records corresponding to iGBS cases with HES hospital admission records (using NHS numbers). Before performing this linkage, we sent patient identifiable data from SGSS records to NHS Digital's Demographic Batch Service to validate recorded NHS numbers, trace missing patient NHS numbers, and obtain dates of death (18). We extracted corresponding HES records for a period 1 calendar year before and after the SGSS surveillance period, January 1, 2014-December 31, 2017. To analyze treatment specialties and Healthcare Resource Group when an iGBS episode had $>1$ associated admission, we selected the admission that was closest to the specimen request date; each admission could be represented by $>1$ treatment specialty. For each
iGBS episode recorded in SGSS, we defined an associated hospital admission as an admission occurring within 7 days of the iGBS specimen request date (proxy for date of diagnosis). Pregnancy-related iGBS episodes were identified by an ICD-10 O or Z370 code for diagnosis at admission. We built multivariable models for risk factors associated with all-cause 30-day and 12-month mortality after iGBS unrelated to pregnancy, including age, sex, socioeconomic deprivation, underlying conditions, and type of hospital admission as a priori risk factors. We performed all analyses in Stata (https://www. stata.com).

\section{Results}

During 2015-2016, a total of 3,156 iGBS episodes in adults $(\geq 15$ years of age) were recorded in England, corresponding to an incidence rate of 3.48 per 100,000 population per year (Table 1). In $87 \%(2,753)$ of recorded episodes, GBS was isolated from a blood culture; the 3 next most common specimen types were from joint $(5.6 \%)$, bone $(2.7 \%)$, and bronchoalveolar lavage $(2.4 \%)$. Of the 3,156 iGBS episodes, $2,999(95.0 \%)$, representing 2,919 patients, could be linked to a hospital admission record within 1 year of iGBS diagnosis and 2,704 (representing 2,647 patients) to an admission within 7 days of iGBS diagnosis (associated hospital admission); of these 2,704 episodes, $479(17.7 \%)$ were pregnancy related (Figure 1). Subtracting this proportion of cases from the 3,156 episodes for England during 2015-2016 gives an estimated incidence rate for iGBS in nonpregnant adults of 2.9/100,000 population/year.

\section{Characteristics of Adults' iGBS Infection}

Analysis of sex and age identified that iGBS was most likely to occur in older patients and women of childbearing age (Figure 2). Most (97.6\%;

\begin{tabular}{lcccccccc}
\hline \multicolumn{2}{l}{ Table 1. Numbers of patients and episodes of iGBS infection among adults in England, 2015-2016* } \\
\hline
\end{tabular}

*iGBS, invasive group B Streptococcus.

†Recurrent iGBS episodes detected during Jan 1, 2015-Dec 31, 2016 based on iGBS episodes for which patient's NHS number was recorded in PHE laboratory surveillance system (3084/3156 episodes)

†Per 100,000 population. Numerator = iGBS episodes/2; denominator = Office for National Statistics mid-2016 population estimates for England (http://www.ons.gov.uk/peoplepopulationandcommunity/populationandmigration/populationestimates/datasets/populationestimatesforukenglandandwales scotlandandnorthernireland) 


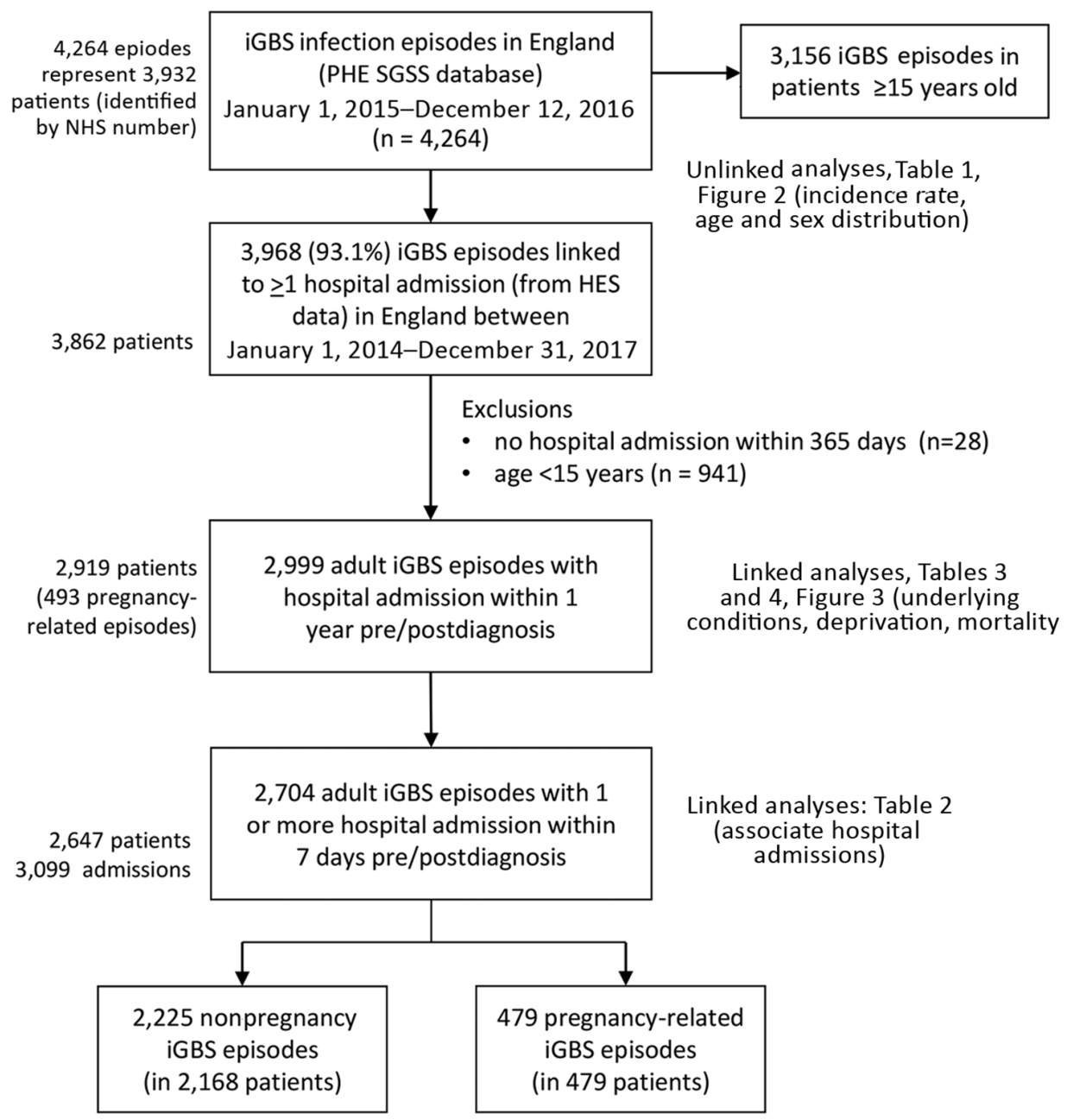

Figure 1. Data flowchart of iGBS infection in England, 2015 and 2016. iGBS, invasive group B Streptococcus.
$2,921 / 2,993)$ patients had a single episode; $1.9 \%$ (58) had 2 and $0.5 \%$ (14) had $\geq 3$ episodes (Table 1 ). There were 493 pregnancy-related iGBS episodes (4.09/10,000 live births). Assessment of incidence (excluding maternity cases) by socioeconomic deprivation identified higher rates in more deprived socioeconomic groups in all but the oldest $(\geq 70$ years) age groups (Figure 3; Appendix Table 1, https:/ / wwwnc.cdc.gov/EID/article/26/6/191141-App1.xlsx). This social gradient was reversed in elderly patients, with adults $>\underline{8} 0$ years of age in the least deprived quintile having a 2.5 -fold higher iGBS rate than in the most deprived quintile (23.8 vs. 9.4/100,000 population), an effect that was more pronounced in male than in female patients (Appendix Table 2). Race and ethnicity was broadly representative of the population of England (Appendix Table 3). The proportion who were black $(4.0 \%)$ was slightly higher than the national figure $(3.3 \%)$, and the proportion who were mixed race was lower $(0.8 \%$ vs. $2.2 \%)$.

\section{Hospital Admission, Time to Diagnosis,} Medical Specialty, and Healthcare Resource Group

Associated admissions (within 7 days of diagnosis) were predominantly through the emergency department $(2,260 / 3,099 ; 72.9 \%)$, except in women 20-39 years of age, for whom most admissions were classified as maternity-related $(493 / 587 ; 84.0 \%$ ) (Table 2). In nonpregnancy episodes, most iGBS diagnoses $(2,064 / 2,225 ; 92.8 \%)$ were from specimens taken within 48 hours of admission, suggesting that the infection was community rather than healthcare associated. In pregnancy-related episodes, $37.4 \%(179 / 479)$ of diagnoses were made $\geq 2$ days after admission (Appendix Table 4). Patients were under the care of 57 different medical specialties (Appendix Table 5); general medicine was the most common specialty $(1,435 / 4,011$; $35.8 \%)$, followed by geriatric medicine $(10.9 \%)$ and obstetrics $(10.9 \%)$. Of specialties with $>50$ associated admissions, the second highest proportion of iGBS diagnosed $\geq 2$ days after admission, after obstetrics and gynecology $(37.4 \%)$, was in urology $(25.7 \%)$. The 


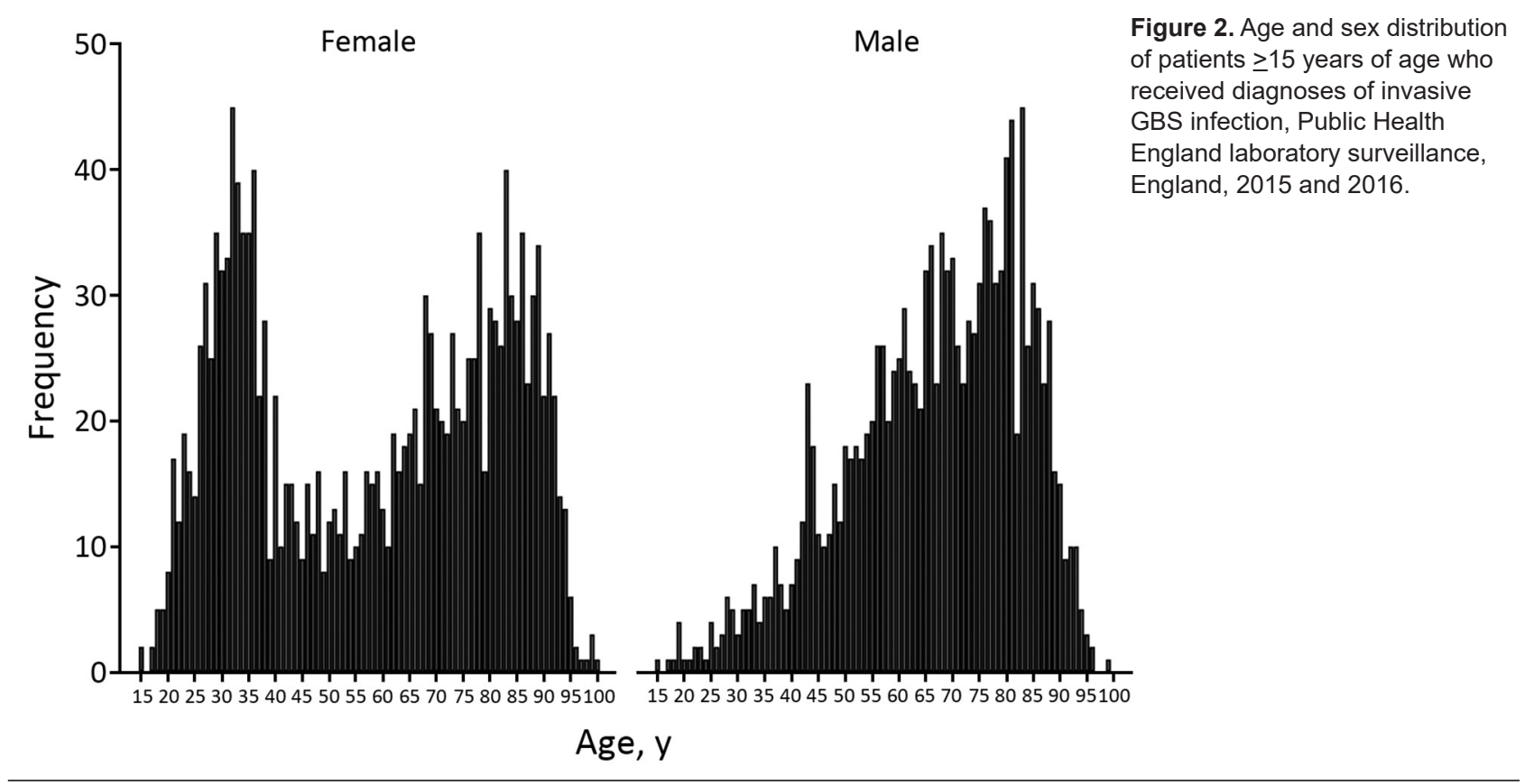

top 4 Healthcare Resource Group subchapters were obstetric medicine (451/2,704; 16.7\%), infectious diseases and immune system disorders (431/2,704; $15.9 \%)$, respiratory system procedures and disorders $(366 / 2,704 ; 13.5 \%)$, and skin disorders (319/2,704; $11.8 \%$ ) (Appendix Table 6).

\section{Underlying Conditions and Surgery $\leq 1$ Year before iGBS Diagnosis}

Analysis of ICD-10 codes recorded in the current and previous ( $\leq 1$ year pre-iGBS) hospital admissions identified underlying conditions as common in nonpregnant adults with iGBS disease (Table 3). Cardiovascular disease was recorded for $57.5 \%$ $(1,440 / 2,506)$ of all nonpregnancy iGBS episodes, lung disease for $42.9 \%(1,076 / 2,506)$, kidney disease for $44.5 \%(1,115 / 2,506)$, and diabetes for $39.9 \%$ $(1,000 / 2,506)$. Prevalences of underlying conditions were much lower in pregnancy-related cases; most (349/493; 70.8\%) had no recorded underlying condition (Appendix Table 7). After diagnostic imaging, testing, and rehabilitation $(1,674 / 2,999 ; 55.8 \%)$, the 4 most commonly recorded current or prior medical procedures by anatomic chapter were arteries and veins (550/2,999; 18.3\%); pregnancy, childbirth, and the puerperium $(470 / 2,999 ; 15.7 \%)$; bones and joints $(439 / 2,999 ; 14.6 \%)$; and urinary $(433 / 2,999 ; 14.4 \%)$ (Appendix Table 8).

\section{All-Cause Mortality after iGBS}

Overall all-cause mortality in nonpregnant adults in the 30 days after an iGBS episode was $12.5 \%$
$(313 / 2,506)$ (Table 4; Appendix Table 9). With extension to the 12 months after diagnosis, all-cause mortality increased to $29.2 \%$ (731/2,506). There were no deaths related to the 493 maternal iGBS episodes. For iGBS unrelated to pregnancy, 30-day mortality after an emergency admission was $13.3 \%(306 / 2,299)$, compared with $3.4 \%(7 / 206)$ for elective admissions $(p<0.001)$. In a multivariable model, the strongest predictors of 30-day all-cause mortality for iGBS unrelated to pregnancy were older age (odds ratio [OR] 3.7 [95\% CI 1.5-9.3] for age $\geq 80$ years compared with 20-29 years), concurrent conditions (OR 5.3 [95\% CI 1.7-16.9] for any of the conditions shown in Table 3 versus none), and emergency admission (OR 3.4 [95\% CI 1.6-7.5] versus nonemergency admission) (Appendix Table 10). Estimates suggested an increased risk of death with higher levels of social deprivation, but these apparent effects were not supported by statistical evidence. In relation to concurrent conditions recorded in the current or prior hospital admission(s), we observed the highest 30-day mortality for iGBS unrelated to pregnancy in patients with kidney disease $(221 / 1,115 ; 19.8 \%)$, followed by cancer $(81 / 437$; $18.5 \%)$, lung disease $(186 / 1,076 ; 17.3 \%)$, and neurologic disorders (138/800; 17.3\%) (Appendix Table 11). We observed similar effects for 12-month mortality (Appendix Tables 12, 13).

\section{Discussion}

We characterized cases of iGBS disease occurring in England over a 2-year period. The annual incidence rate of 3.48/100,000 population during 2015-2016 


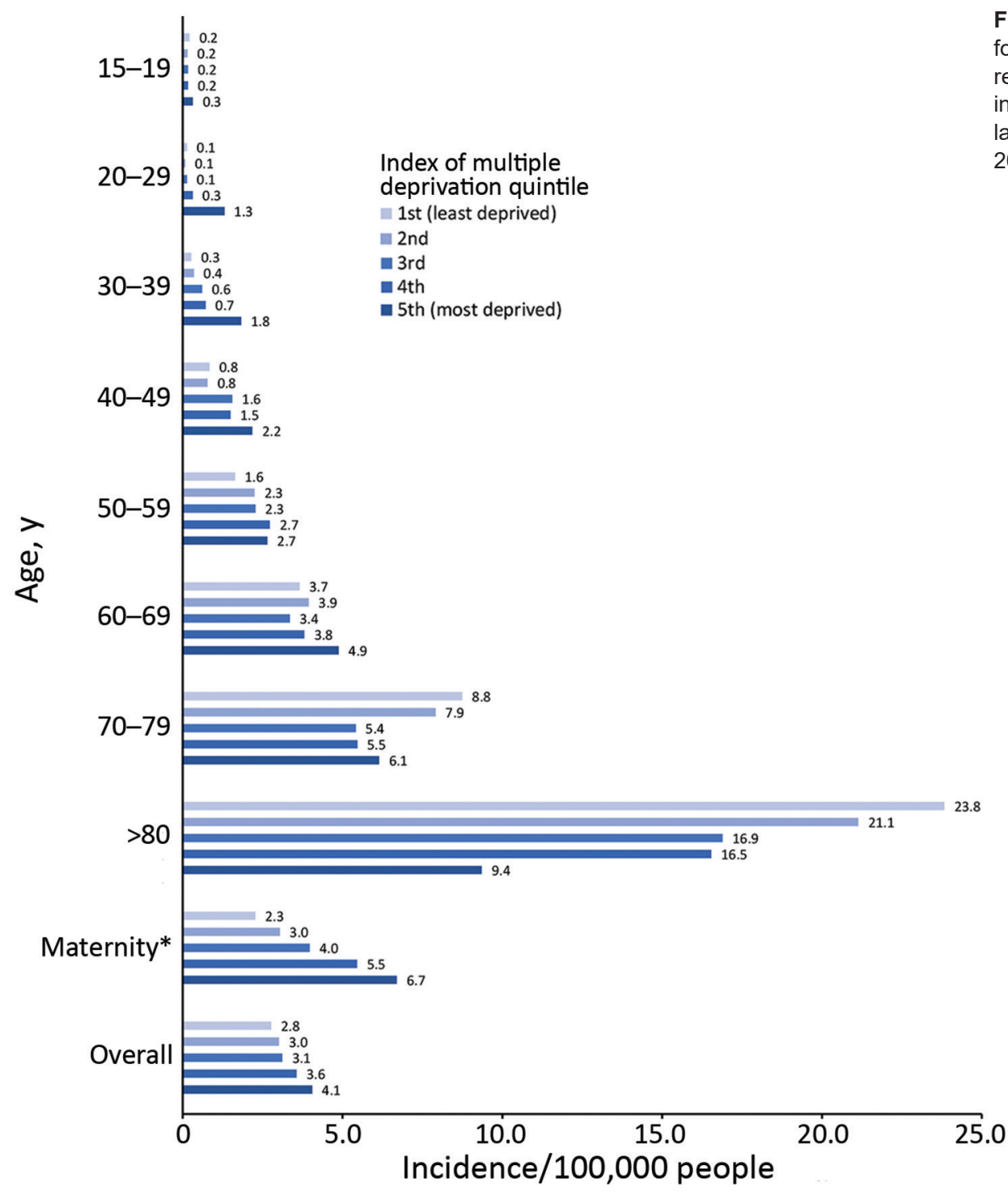

Figure 3. Social deprivation quintiles for patients $\geq 15$ years of age who received diagnoses of invasive GBS infection, Public Health England laboratory surveillance, England, 2015 and 2016.

suggests a continuation of the trend in adults during 1991-2010, when incidence increased from 0.92 to $2.39 / 100,000$ population (7). This trend is largely attributable to cases in adults, particularly the elderly. A prominent feature of the iGBS age distribution in England is the relatively higher incidence among women of childbearing age, as also seen in some other countries (8). Overall incidence in England for 2015-2016 $(\approx 3 / 100,000$ population, excluding maternity cases) was one third the rate in nonpregnant adults in the United States for the same period (6). This finding is the opposite of the reported rates for pregnancy-related iGBS, which are lower in the United States $(0.1 / 1,000$ live births) compared with England (0.3/1,000 live births) (19), possibly because antenatal GBS screening in the United States leads to widespread use of intrapartum antimicrobial prophylaxis.
Prevalence of underlying conditions appeared to be much higher in iGBS cases than in the adult population in England (20). For example, $40 \%$ of persons with iGBS had diabetes (compared with $7 \%$ in the general population), $17 \%$ cancer $(2 \%), 58 \%$ cardiovascular disease $(1 \%), 45 \%$ kidney disease $(4 \%)$, and $30 \%$ arthritis (1\%). These findings are consistent with other studies of iGBS in adults $(5,6,8-11,21,22)$; the increasing prevalence of predisposing medical conditions in the adult population may account for rising rates of iGBS disease (4-8). Vaccination to prevent iGBS in adults could be a key component of future preventive measures if appropriately targeted. The costeffectiveness of GBS vaccination has been evaluated (favorably) in relation to neonatal disease $(23,24)$, but health economic studies encompassing nonpregnancy-associated adult disease are lacking (25). Health 
Table 2. Hospital admissions among adult patients with iGBS infection in England, 2015-2016*

\begin{tabular}{|c|c|c|c|c|c|c|c|}
\hline \multirow[b]{2}{*}{ Age, $y$} & \multicolumn{3}{|c|}{ Male patients, no. (\%) } & \multicolumn{4}{|c|}{ Female patients, no. (\%) } \\
\hline & No. admissions & Elective & Emergency & No. admissions & Elective & Emergency & Maternity \\
\hline $15-19$ & 4 & $2(50.0)$ & $2(50.0)$ & 14 & 0 & $6(42.9)$ & $8(57.1)$ \\
\hline 20-29 & 29 & $2(6.9)$ & $27(93.1)$ & 237 & $5(2.1)$ & $27(11.4)$ & $205(86.5)$ \\
\hline 30-39 & 54 & $2(3.7)$ & $50(92.6)$ & 350 & $10(2.9)$ & $51(14.6)$ & $288(82.3)$ \\
\hline $40-49$ & 121 & $9(7.4)$ & $109(90.1)$ & 140 & $12(8.6)$ & $81(57.9)$ & 46 (32.9) \\
\hline $50-59$ & 204 & $30(14.7)$ & $170(83.3)$ & 140 & $34(24.3)$ & $105(75.0)$ & $1(0.7)$ \\
\hline $60-69$ & 292 & $35(12.0)$ & $250(85.6)$ & 197 & $25(12.7)$ & $171(86.8)$ & 0 \\
\hline $70-79$ & 307 & $23(7.5)$ & $283(92.2)$ & 230 & $16(7.0)$ & $210(91.3)$ & 0 \\
\hline$\geq 80$ & 366 & $26(7.1)$ & $331(90.4)$ & 414 & $19(4.6)$ & $387(93.5)$ & 0 \\
\hline$\overline{\text { Total }}$ & 1,377 & $129(9.4)$ & $1,222(88.7)$ & 1,722 & $121(7.0)$ & $1,038(60.3)$ & $548(31.8)$ \\
\hline
\end{tabular}

economic studies of GBS vaccination to prevent GBS disease in adults would need to take into account all manifestations of GBS disease, including noninvasive infections (26) and the possible prevention of antimicrobial resistance $(6,27,28)$.

Further prevention measures could be identified through improved understanding of the role of healthcare interventions and the wider hospital environment in enabling disease occurrence (29). Although most of the cases in this study were diagnosed at admission, suggesting community acquisition, the high prevalence of underlying conditions and the numbers of patients having medical procedures in the preceding year suggest that prior healthcare exposure was likely for a sizable proportion of patients.

In our study, 30 -day mortality $(12 \%)$ was higher than the case-fatality rate reported recently from a population-based study in the United States (6\%) (6), but we included all-cause deaths within 30 days of iGBS rather than deaths occurring during hospitalization for iGBS. The high 12-month mortality rate that we observed in the youngest (15-19 years) age group (5/12 cases) reflected deaths in young adults with other medical conditions (2 with cancer, 1 with cardiovascular disease, 1 with multiple concurrent conditions).
The steep gradients observed over quintiles of social deprivation, with more deprived quintiles having higher iGBS incidence up to age 60-69 years but lower incidence thereafter, could be attributed partly to concurrent conditions, although overall prevalence of such conditions did not differ substantially across the quintiles. Social gradients have been reported for different infectious diseases in England (30), including incidence increasing with deprivation for invasive group A Streptococcus, meningococcal, and pneumococcal infection. Incidence of community-acquired pneumonia in older ( $\geq 65$ years of age) adults in the United Kingdom showed a steep increase with level of deprivation (31), the opposite of the trend that we observed for iGBS in adults $\geq 70$ years of age.

The trend that we observed of increasing maternity-related iGBS incidence with higher levels of social deprivation is entirely consistent with the trend reported for risk of severe maternal sepsis in the United Kingdom (32). The potential for iGBS prevention in this group is supported by a study showing that $\geq 70 \%$ of women across all social grades would be likely to accept antenatal GBS vaccination (33).

Although PHE's microbiology surveillance database has national coverage (34), reporting of GBS infection is not mandatory, and the completeness of reporting is unknown. A comparison of MRSA and

Table 3. Underlying conditions among adult patients with invasive GBS (iGBS) infection unrelated to pregnancy in England, 2015-2016*

\begin{tabular}{|c|c|c|c|c|c|c|c|c|c|}
\hline \multirow[b]{2}{*}{ Conditions } & \multicolumn{8}{|c|}{ Age, y } & \multirow[b]{2}{*}{ Total } \\
\hline & $15-19$ & $20-29$ & $30-39$ & $40-49$ & $50-59$ & $60-69$ & $70-79$ & $\geq 80$ & \\
\hline No. iGBS episodes & 12 & 49 & 98 & 204 & 339 & 474 & 545 & $\overline{785}$ & 2,506 \\
\hline Diabetes & $1(8.3)$ & $5(10.2)$ & $17(17.4)$ & $62(30.4)$ & $162(47.8)$ & $212(44.7)$ & $267(49.0)$ & $274(34.9)$ & $1,000(39.7)$ \\
\hline $\begin{array}{l}\text { Peripheral vascular } \\
\text { disease }\end{array}$ & $1(8.3)$ & $5(10.2)$ & 31 (31.6) & $46(22.6)$ & $113(33.3)$ & $154(32.5)$ & $203(37.3)$ & $289(36.8)$ & $842(33.6)$ \\
\hline Cancer & $2(16.7)$ & $2(4.1)$ & $1(1.0)$ & $28(13.7)$ & $57(16.8)$ & 77 (16.2) & $107(19.6)$ & $163(20.8)$ & $437(17.4)$ \\
\hline Cardiovascular disease & $3(25.0)$ & $12(24.5)$ & $32(32.7)$ & $58(28.4)$ & $125(36.9)$ & $249(52.5)$ & $355(65.1)$ & $606(77.2)$ & $1,440(57.5)$ \\
\hline Lung disease & $5(41.7)$ & $20(40.8)$ & $39(39.8)$ & $72(35.3)$ & $148(43.7)$ & $193(40.7)$ & $242(44.4)$ & $357(45.5)$ & $1,076(42.9)$ \\
\hline Kidney disease & $2(16.7)$ & $9(18.4)$ & $19(19.4)$ & $69(33.8)$ & $117(34.5)$ & $197(41.6)$ & $268(49.2)$ & $434(55.3)$ & $1,115(44.5)$ \\
\hline Neurologic disorders & $2(16.7)$ & $11(22.5)$ & 21 (21.4) & $53(26.0)$ & $111(32.7)$ & $124(26.2)$ & 167 (30.6) & $311(39.6)$ & $800(31.9)$ \\
\hline Arthritis & 0 & $5(10.2)$ & $12(12.2)$ & $42(20.6)$ & $74(21.8)$ & $125(26.4)$ & 189 (34.7) & $294(37.5)$ & 741 (29.6) \\
\hline None of these & $3(25.0)$ & $12(24.5)$ & $23(23.5)$ & $28(13.7)$ & $27(8.0)$ & $39(8.2)$ & $17(3.1)$ & $15(1.9)$ & $164(6.5)$ \\
\hline
\end{tabular}


Table 4. All-cause 30-day and 12-month mortality among adult patients with iGBS infection in England, 2015-2016*

\begin{tabular}{|c|c|c|c|c|c|c|c|c|}
\hline \multirow[b]{2}{*}{ Age, $y$} & \multicolumn{4}{|c|}{ Male patients } & \multicolumn{4}{|c|}{ Female patients, excluding pregnancy-related episodes } \\
\hline & $\begin{array}{l}\text { No. iGBS } \\
\text { episodes }\end{array}$ & $\begin{array}{c}\text { All-cause } \\
\text { deaths within } \\
30 \mathrm{~d}, \text { no. }(\%)\end{array}$ & $\begin{array}{c}\text { All-cause } \\
\text { deaths within } 1 \\
y, \text { no. }(\%)\end{array}$ & $\begin{array}{c}\text { Median } \\
\text { (IQR) time to } \\
\text { death, d }\end{array}$ & $\begin{array}{l}\text { No. iGBS } \\
\text { episodes }\end{array}$ & $\begin{array}{c}\text { All-cause } \\
\text { deaths within } \\
30 \mathrm{~d}, \text { no. }(\%)\end{array}$ & $\begin{array}{c}\text { All-cause } \\
\text { deaths within } \\
1 \mathrm{y}, \text { no. }(\%)\end{array}$ & $\begin{array}{l}\text { Median (IQR) } \\
\text { time to death, } \\
\text { d }\end{array}$ \\
\hline $15-19$ & 6 & 0 & $3(50.0)$ & $39(33-170)$ & 6 & 2 (33.3) & $2(33.3)$ & $4(2-6)$ \\
\hline $20-29$ & 27 & $1(3.7)$ & $2(7.4)$ & $144(2-285)$ & 22 & $0(0.0)$ & $2(9.1)$ & $179(33-325)$ \\
\hline $30-39$ & 59 & $4(6.8)$ & 7 (11.9) & $3(1-159)$ & 39 & $1(2.6)$ & $2(5.1)$ & $58(2-113)$ \\
\hline $40-49$ & 120 & 14 (11.7) & $27(22.5)$ & $26(2-68)$ & 84 & $3(3.6)$ & $8(9.5)$ & $37(15-124)$ \\
\hline $50-59$ & 212 & $21(9.9)$ & $44(20.8)$ & $39(12-135)$ & 127 & $3(2.4)$ & $15(11.8)$ & $80(40-177)$ \\
\hline $60-69$ & 281 & $21(7.5)$ & $51(18.1)$ & $45(11-168)$ & 193 & $21(10.9)$ & $46(23.8)$ & $72(3-177)$ \\
\hline 70-79 & 310 & $38(12.3)$ & $93(30.0)$ & $57(13-145)$ & 235 & $34(14.5)$ & $66(28.1)$ & $30(8-119)$ \\
\hline$\geq 80$ & 359 & $77(21.4)$ & $177(49.3)$ & $41(10-188)$ & 426 & $73(17.1)$ & $186(43.7)$ & $54(8-136)$ \\
\hline$\overline{\text { Total }}$ & 1,374 & $176(12.8)$ & 404 (29.4) & $44(10-167)$ & 1,132 & $137(12.1)$ & $327(28.9)$ & $53(8-138)$ \\
\hline
\end{tabular}

E. coli data reported to a separate mandatory surveillance system showed that voluntary reporting represented $>80 \%$ of records for bacteremia caused by these 2 species $(35,36)$. A further limitation of our analysis is that, even with linkage to hospital episode data, we lacked sufficiently detailed clinical information on the manifestations and severity of the iGBS cases and outcomes resulting from GBS. This inability to ascertain clinical case characteristics constrained us to analyzing iGBS patients as a homogeneous group, which they will not be in practice $(2,5,6,9,37)$. Although bronchoalveolar lavage is not universally considered a sterile site sample, we included these specimens in our iGBS case definition to capture lower respiratory tract infections. Although we cannot completely discount the possibility that some of the respiratory isolates were contaminants, national standards for microbiology laboratories provide guidelines to differentiate these from clinically significant infections (38).

In conclusion, incidence of iGBS disease in adults continues to increase in England, and high risk groups include the elderly, pregnant women, and adults with underlying conditions. Most nonpregnant adults have emergency cases, and all-cause mortality is high (one quarter of cases). Reasons for the strong social gradients at different ages merit further investigation, as does the potential for prevention of iGBS through vaccination.

\section{Acknowledgments}

We thank Nick Hinton at Public Health England for retrieval and linkage of Hospital Episode Statistics (HES) data.

This study was funded by Pfizer Inc.

\section{About the Author}

Dr. Collin is a senior scientist in the Healthcare-Associated Infection and Antimicrobial Resistance Division of Public Health England, where his primary research interest is in the epidemiology of group B Streptococcus infection.

\section{References}

1. Kernéis S, Plainvert C, Barnier JP, Tazi A, Dmytruk N, Gislain B, et al. Clinical and microbiological features associated with group B Streptococcus bone and joint infections, France 2004-2014. Eur J Clin Microbiol Infect Dis. 2017;36:1679-84. https:// doi.org/10.1007/s10096-017-2983-y

2. Chaiwarith R, Jullaket W, Bunchoo M, Nuntachit N, Sirisanthana T, Supparatpinyo K. Streptococcus agalactiae in adults at Chiang Mai University Hospital: a retrospective study. BMC Infect Dis. 2011;11:149. https:// doi.org/ 10.1186/1471-2334-11-149

3. Falagas ME, Rosmarakis ES, Avramopoulos I, Vakalis N. Streptococcus agalactiae infections in non-pregnant adults: single center experience of a growing clinical problem. Med Sci Monit. 2006;12:CR447-51.

4. Bjornsdottir ES, Martins ER, Erlendsdottir H, Haraldsson G, Melo-Cristino J, Kristinsson KG, et al. Changing epidemiology of group B streptococcal infections among adults in Iceland: 1975-2014. Clin Microbiol Infect. 2016;22:379.e9-16. https:// doi.org/10.1016/j.cmi.2015.11.020

5. Skoff TH, Farley MM, Petit S, Craig AS, Schaffner W, Gershman K, et al. Increasing burden of invasive group B streptococcal disease in nonpregnant adults, 1990-2007. Clin Infect Dis. 2009;49:85-92. https:/ / doi.org/10.1086/599369

6. Francois Watkins LK, McGee L, Schrag SJ, Beall B, Jain JH, Pondo T, et al. Epidemiology of invasive group B streptococcal infections among nonpregnant adults in the United States, 2008-2016. JAMA Intern Med. 2019;179:479_ 88. https://doi.org/10.1001/jamainternmed.2018.7269

7. Lamagni TL, Keshishian C, Efstratiou A, Guy R, Henderson KL, Broughton K, et al. Emerging trends in the epidemiology of invasive group B streptococcal disease in England and Wales, 1991-2010. Clin Infect Dis. 2013;57:682-8. https://doi.org/10.1093/cid/cit337

8. Ballard MS, Schønheyder HC, Knudsen JD, Lyytikäinen O, Dryden M, Kennedy KJ, et al.; International Bacteremia Surveillance Collaborative. The changing epidemiology of group B streptococcus bloodstream infection: a multi-national population-based assessment. Infect Dis (Lond). 2016;48:386-91. https:/ / doi.org/10.3109/23744235.2 015.1131330

9. Camuset G, Picot S, Jaubert J, Borgherini G, Ferdynus C, Foucher A, et al. Invasive group B streptococcal disease in non-pregnant adults, Réunion Island, 2011. Int J Infect Dis. 2015;35:46-50. https://doi.org/10.1016/j.ijid.2015.04.006

10. Lefebvre N, Forestier E, Mohseni-Zadeh M, Remy V, Lesens O, Kuhnert C, et al. Invasive Streptococcus agalactiae infections in non-pregnant adults [in French]. Med Mal Infect. 2007;37:796-801. https:/ / doi.org/10.1016/ j.medmal.2007.04.003 
11. Huang PY, Lee MH, Yang CC, Leu HS. Group B streptococcal bacteremia in non-pregnant adults. J Microbiol Immunol Infect. 2006;39:237-41.

12. Vekemans J, Moorthy V, Friede M, Alderson MR, Sobanjo-Ter Meulen A, Baker CJ, et al. Maternal immunization against Group B streptococcus: World Health Organization research and development technological roadmap and preferred product characteristics. Vaccine. 2019;37:7391-3. https:/ / doi.org/10.1016/ j.vaccine.2017.09.087

13. Le Doare K, Heath PT. An overview of global GBS epidemiology. Vaccine. 2013;31(Suppl 4):D7-12. https://doi.org/10.1016/j.vaccine.2013.01.009

14. Freeman R, Charlett A, Hopkins S, O'Connell AM, Andrews N, Freed J, et al. Evaluation of a national microbiological surveillance system to inform automated outbreak detection. J Infect. 2013;67:378-84. https:/ / doi.org/ 10.1016/j.jinf.2013.07.021

15. PHE Second Generation Surveillance System (SGSS). Laboratory reporting to Public Health England: a guide for diagnostic laboratories. London: Public Health England; 2016.

16. Public Health England. Laboratory surveillance of pyogenic and non-pyogenic streptococcal bacteraemia in England, Wales and Northern Ireland: 2016. London: Public Health England; 2017.

17. Herbert A, Wijlaars L, Zylbersztejn A, Cromwell D, Hardelid P. Data resource profile: Hospital Episode Statistics Admitted Patient Care (HES APC). Int J Epidemiol. 2017;46:1093-1093i. https://doi.org/10.1093/ije/dyx015

18. NHS Digital. Demographics Batch Service Bureau (DBSB): NHS number batch tracing. London: Health and Social Care Information Centre; 2017.

19. Hall J, Adams NH, Bartlett L, Seale AC, Lamagni T, Bianchi-Jassir F, et al. Maternal disease with group B Streptococcus and serotype distribution worldwide: systematic review and meta-analyses. Clin Infect Dis. 2017;65(suppl_2):S112-24. https://doi.org/10.1093/cid/ cix660

20. NHS Digital. Quality and Outcomes Framework (QOF) 2015-16. 2016 [cited January 2019]. http:/ / digital.nhs.uk/ data-and-information/publications/statistical/quality-andoutcomes-framework-achievement-prevalence-and-exceptions-data/quality-and-outcomes-framework-qof-2015-16

21. Schwartz B, Schuchat A, Oxtoby MJ, Cochi SL, Hightower A, Broome CV. Invasive group B streptococcal disease in adults. A population-based study in metropolitan Atlanta. JAMA. 1991;266:1112-4. https://doi.org/10.1001/ jama.1991.03470080082034

22. Farley MM, Harvey RC, Stull T, Smith JD, Schuchat A, Wenger JD, et al. A population-based assessment of invasive disease due to group B Streptococcus in nonpregnant adults. N Engl J Med. 1993;328:1807-11. https:/ / doi.org/10.1056/ NEJM199306243282503

23. Giorgakoudi K, O'Sullivan C, Heath PT, Ladhani S, Lamagni T, Ramsay M, et al. Cost-effectiveness analysis of maternal immunisation against group B Streptococcus (GBS) disease: a modelling study. Vaccine. 2018;36:7033-42. https://doi.org/10.1016/j.vaccine.2018.09.058

24. Kim SY, Nguyen C, Russell LB, Tomczyk S, Abdul-Hakeem F, Schrag SJ, et al. Cost-effectiveness of a potential group B streptococcal vaccine for pregnant women in the United States. Vaccine. 2017;35:6238-47. https:/ / doi.org/10.1016/ j.vaccine.2017.08.085

25. Cannon JW, Jack S, Wu Y, Zhang J, Baker MG, Geelhoed E, et al. An economic case for a vaccine to prevent group A
Streptococcus skin infections. Vaccine. 2018;36:6968-78. https:// doi.org/10.1016/j.vaccine.2018.10.001

26. Collin SM, Shetty N, Guy R, Nyaga VN, Bull A, Richards MJ, et al. Group B Streptococcus in surgical site and non-invasive bacterial infections worldwide: a systematic review and meta-analysis. Int J Infect Dis. 2019;83:116-29. https:/ / doi.org/10.1016/j.ijid.2019.04.017

27. Sevilla JP, Bloom DE, Cadarette D, Jit M, Lipsitch M. Toward economic evaluation of the value of vaccines and other health technologies in addressing AMR. Proc Natl Acad Sci U S A. 2018;115:12911-9. https:/ / doi.org/10.1073/ pnas.1717161115

28. Kitamura M, Kimura K, Ido A, Seki T, Banno H, Jin W, et al. Relatively high rates of cefotaxime- and ceftriaxone-nonsusceptible isolates among group B streptococci with reduced penicillin susceptibility (PRGBS) in Japan. J Antimicrob Chemother. 2019;74:931-4. https://doi.org/ 10.1093/jac/dky542

29. Collin SM, Lamb P, Jauneikaite E, Le Doare K, Creti R, Berardi A, et al. Hospital clusters of invasive group B streptococcal disease: a systematic review. J Infect. 2019;79:521-7. https:/ / doi.org/10.1016/j.jinf.2019.11.008

30. Hughes GJ, Gorton R. Inequalities in the incidence of infectious disease in the north east of England: a population-based study. Epidemiol Infect. 2015;143:189-201. https://doi.org/10.1017/S0950268814000533

31. Millett ER, Quint JK, Smeeth L, Daniel RM, Thomas SL. Incidence of community-acquired lower respiratory tract infections and pneumonia among older adults in the United Kingdom: a population-based study. PLoS One. 2013;8:e75131. https:/ / doi.org/10.1371/journal. pone. 0075131

32. Acosta CD, Harrison DA, Rowan K, Lucas DN, Kurinczuk JJ, Knight M. Maternal morbidity and mortality from severe sepsis: a national cohort study. BMJ Open. 2016;6:e012323. https://doi.org/10.1136/ bmjopen-2016-012323

33. McQuaid F, Jones C, Stevens Z, Plumb J, Hughes R, Bedford H, et al. Factors influencing women's attitudes towards antenatal vaccines, group B Streptococcus and clinical trial participation in pregnancy: an online survey. BMJ Open. 2016;6:e10790. https://doi.org/10.1136/ bmjopen-2015-010790

34. Public Health England. English Surveillance Programme for Antimicrobial Utilisation and Resistance (ESPAUR). London: Public Health England; 2018.

35. Public Health England. Laboratory surveillance of Staphylococcus aureus bacteraemia in England, Wales and Northern Ireland: 2017. London: Public Health England; 2018.

36. Public Health England. Laboratory surveillance of Escherichia coli bacteraemia in England, Wales and Northern Ireland: 2017. London: Public Health England; 2018.

37. High KP, Edwards MS, Baker CJ. Group B streptococcal infections in elderly adults. Clin Infect Dis. 2005;41:839-47. https://doi.org/10.1086/432804

38. UK Standards for Microbiology Investigations. Investigation of bronchoalveolar lavage, sputum and associated specimens. London: Public Health England; 2019.

Address for correspondence: Simon M. Collin, HealthcareAssociated Infection and Antimicrobial Resistance Division, National Infection Service, Public Health England, 61 Colindale Ave, London NW9 5EQ, UK; email: simon.collin@phe.gov.uk 